\title{
Sosialisasi DAGUSIBU (Dapatkan, Gunakan, Simpan, Buang) obat dengan benar pada guru dan karyawan SMA Theresiana I Semarang
}

\author{
${ }^{1}$ Anasthasia Pujiastuti*, ${ }^{2}$ Monica Kristiani \\ ${ }^{1,2}$ Program Studi DIII Farmasi, Politeknik Katolik Mangunwijaya, Semarang, Indonesia \\ *Corresponding Author \\ thasia_anas@yahoo.com
}

\begin{abstract}
Abstrak
Berbagai masalah kesehatan, khususnya terkait obat masih ditemui di masyarakat. Berbagai permasalahan terkait obat dapat dikarenakan masyarakat kurang paham tentang penggunaan dan penanganan obat dengan benar. Salah satu cara pengelolaan obat yang baik dan benar adalah dengan menerapkan program DAGUSIBU (DApatkan, GUnakan, SImpan, BUang). Berdasarkan informasi yang diperoleh, guru dan karyawan SMA Theresiana I Semarang belum pernah mendapatkan informasi tentang DAGUSIBU sehingga perlu dilakukan sosialisasi tentang DAGUSIBU. Adanya kegiatan ini diharapkan para guru dan karyawan SMA Theresiana I Semarang dapat membagikan informasi tentang penggunaan dan penanganan obat yang benar kepada anggota keluarganya serta siswa siswi SMA Theresiana I Semarang. Metode yang digunakan dalam kegiatan ini adalah pengenalan masalah, pelaksanaan sosialisasi DAGUSIBU dengan cara penyuluhan, diskusi interaktif, dan pambagian buku saku DAGUSIBU. Kegiatan sosialisasi tentang DAGUSIBU berjalan dengan lancar. Tingkat kehadiran peserta sebanyak $89,3 \%$. Para peserta yang hadir sangat antusias dalam mendengarkan penjelasan dan aktif bertanya terkait penggunaan obat dan penanganannya. Hal ini dapat menunjang terwujudnya program pemerintah dalam peningkatan pelayanan kesehatan bagi masyarakat. Sosialisasi ini meningkatkan pemahaman peserta tentang pengelolaan obat dengan benar, diharapkan peserta dapat menerapkan pengetahuan yang telah diperoleh dalam lingkungan keluarga dan masyarakat.
\end{abstract}

Kata Kunci: DAGUSIBU, obat, sosialisasi.

\begin{abstract}
Some parts of our society are having problems with handling drugs properly. One of the causes is not all people understand how to heal their sickness with many kinds of drugs. Various drugs-society related problems can be caused by people's lack of understanding about the use and handling of drugs correctly. One way to inform society how to manage drugs properly is to implement the DAGUSIBU (DApatkan, GUnakan, SImpan, BUang). Based on the information obtained, the teachers and employees of SMA Theresiana I Semarang have never received information about DAGUSIBU. That's why it is necessary to socialize DAGUSIBU in their community. The purpose of this activity is to make them understand and share information about the correct way to receive, apply, install and waste the medicines among their family members and students. The method used in this dissemination is ellucidation by socializing problems of handling drugs improperly
\end{abstract}


as introduction and then the implementation of DAGUSIBU by means of counseling, interactive discussions, and the distribution of DAGUSIBU pocket books. The dissemination about DAGUSIBU went smoothly. The attendance rate was $89.3 \%$. The participants were very enthusiastic in listening to the explanation and actively asked about drugs-society related problems. This can support the realization of government programs in improving health services for the community. This socialization increases participants' understanding of drug management correctly, it is expected that participants can apply the knowledge gained in the family and community environment.

Keywords: DAGUSIBU, drug, socialization.

\section{PENDAHULUAN}

DAGUSIBU (DApatkan, GUnakan, SImpan, BUang) adalah Program Gerakan Keluarga Sadar Obat yang diprakarsai oleh Ikatan Apoteker Indonesia dalam mencapai pemahaman dan kesadaran masyarakat terhadap penggunaan obat dengan benar (PP IAI, 2014). DAGUSIBU merupakan salah satu upaya peningkatan kesehatan bagi masyarakat yang diselenggarakan melalui kegiatan pelayanan kesehatan oleh tenaga kefarmasian. Hal tersebut sesuai dengan yang tercantum dalam Peraturan Pemerintah Nomor 51 tentang Pekerjaan Kefarmasian pada Bab I Pasal 1 yang menyatakan bahwa pelayanan kefarmasian adalah suatu pelayanan langsung dan bertanggung jawab kepada pasien yang berkaitan dengan sediaan farmasi dengan maksud mencapai hasil yang pasti untuk meningkatkan mutu kehidupan pasien. Pelayanan kesehatan yang dapat diberikan tenaga kefarmasian kepada masyarakat antara lain dengan melakukan kegiatan pemberian informasi tentang penggunaan dan penyimpanan sediaan farmasi dan alat kesehatan. Setiap warga negara berhak untuk mendapatkan pelayanan kesehatan yang baik termasuk informasi tentang penanganan obat yang benar. Hal tersebut sesuai dengan yang tercantum dalam Undang-undang Nomor 36 Tahun 2009 yang mana telah ditetapkan upaya kesehatan sebagai kegiatan yang bertujuan untuk meningkatkan derajat kesehatan yang setinggitingginya bagi masyarakat dan salah satu kegiatan upaya kesehatan adalah pengamanan dan penggunaan sediaan farmasi dan alat kesehatan.

Derajat kesehatan yang setinggi-tingginya seperti harapan yang tertuang dalam UndangUndang Kesehatan sampai saat ini pelaksanaannya masih kurang maksimal. Berbagai masalah kesehatan, khususnya terkait obat masih ditemui di masyarakat. Permasalahan tersebut antara lain penyalahgunaan obat, terjadinya efek samping obat dari yang paling ringan sampai dengan kebutaan dan kematian, beredarnya obat palsu, narkoba, dan bahan berbahaya lainnya (PP IAI, 2014). Kasus penyalahgunaan obat yang terjadi di masyarakat contohnya adalah narkoba, berdasarkan penelitian yang dilakukan oleh Jimmy (2015) yang berjudul Penyalahgunaan 
Narkoba di Kalangan Remaja, diketahui bahwa faktor yang paling dominan sebagai penyebabnya adalah pergaulan. Oleh karena itu, perlu adanya kerja sama yang baik oleh masyarakat dan pemerintah agar penyalahgunaan narkoba dapat dicegah sejak dini (Permatasari, 2017). Adanya berbagai permasalahan tersebut dapat juga dikarenakan masyarakat kurang paham tentang penggunaan dan penanganan obat dengan benar. Salah satu cara pengelolaan obat yang baik dan benar adalah dengan menerapkan program DAGUSIBU. Cara ini menjelaskan tata cara pengelolaan obat dari awal mendapatkan obat hingga saat obat sudah tidak dikonsumsi lagi dan akhirnya dibuang. Dengan berbagai pertimbangan di atas maka masyarakat perlu tahu akan pentingnya pengelolaan obat mulai dari mereka mendapatkan resep hingga membuangnya jika tidak diperlukan. Dengan demikian, dampak dari kesalahan penyalahgunaan obat oleh masyarakat dapat dicegah.

Adanya berbagai masalah tersebut maka diperlukan keikutsertaan tenaga kefarmasian dalam mewujudkan kesehatan masyarakat dengan ambil bagian dalam upaya peningkatan pelayanan kesehatan. Upaya peningkatan pelayanan kesehatan tersebut antara lain dapat dilakukan dengan memberikan informasi tentang penggunaan dan penanganan obat yang benar melalui sosialisasi dengan cara penyuluhan dan pembagian buku saku tentang DAGUSIBU. Peningkatan pelayanan kesehatan dapat diberikan pada seluruh lapisan masyarakat antara lain pada guru dan karyawan Sekolah Menengah Atas.

Berdasarkan observasi tim pelaksana program pengabdian masyarakat diketahui bahwa guru dan karyawan SMA Theresiana I Semarang belum pernah mendapatkan informasi tentang DAGUSIBU dan pengetahuanterkait penggunaan dan penanganan obat masih kurang. Tim pelaksana program memandang perlu untuk dilakukan sosialisasi pada guru dan karyawan SMA Theresiana I Semarang. Hasil sosialisasi diharapkan para guru dan karyawan SMA Theresiana I dapat membagikan informasi tentang penggunaan dan penanganan obat yang benar kepada anggota keluarganya serta siswa siswi SMA Theresiana I. Diharapkan setiap guru dan karyawan SMA I Theresiana lebih paham tentang penggunaan dan penanganan obat yang benar dimulai dari lingkungan terkecil yaitu keluarga. Dengan demikian, program Gerakan Keluarga Sadar Obat (GKSO) yang diprakarsai oleh Ikatan Apoteker Indonesia (IAI) untuk meningkatkan kualitas hidup masyarakat dalam upaya mencapai derajat kesehatan yang setinggi-tingginya sebagai komitmen dalam melaksanakan amanat Undang-undang Nomor 36 Tahun 2009 tentang Kesehatan dapat tercapai. 


\section{METODE}

Metode yang digunakan dalam kegiatan pengabdian masyarakat ini yaitu metode pemberdayaan masyarakat partisipatif dengan model Particatory Rural Appraisal (PRA), yaitu metode yang menekankan keterlibatan masyarakat dalam semua kegiatan yang dilakukan (Lutfiyati, dkk., 2017).Tahapan dalam pelaksanaan program pengabdian masyarakat ini meliputi:

1. Pengenalan masalah

Tim pelaksana melakukan survei pada mitra (SMA Theresiana I Semarang) untuk melakukan pengenalan masalah yang dihadapi mitra terkait pengelolaan obat. Berdasarkan hasil penelusuran diketahui bahwa guru dan karyawan SMA Theresiana I Semarang tingkat pengetahuannya tentang pengelolaan obat masih relatif rendah dan belum pernah mendapatkan sosialisasi tentang DAGUSIBU. Tim pengusul memberikan alternatif penyelesaian masalah dengan cara memberikan sosialisasi tentang DAGUSIBU.

2. Sosialisasi DAGUSIBU dengan cara penyuluhan

Kegiatan sosialisasi DAGUSIBU dilaksanakan setelah semua perijinan dan peralatan disiapkan. Kegiatan dilaksanakan di SMA Theresiana I Semarang. Pelaksanaan penyuluhan dilakukan oleh ketua dan angota pelaksana pengabdian dengan menjelaskan tentang penggunaan dan penanganan obat yang benar. Penyuluhan dilakukan dengan media bantu Power Point, sehingga peserta dapat mengetahui dengan jelas perbedaan jenis-jenis obat yang beredar di masyarakat. Materi yang disampaikan meliputi:

- DAGUSIBU (DApatkan, GUnakan, SImpan, BUang) obat dengan benar,

- Penggolongan obat,

- Bahaya penyalahgunaan narkotika dan psikotropika,

- Penggunaan obat tradisional dan kosmetika yang baik.

3. Diskusi dan tanya jawab

Pada sesi diskusi dan tanya jawab, peserta dipersilakan bertanya berbagai hal terkait materi yang disampaikan ataupun permasalahan tentang penggunaan dan penanganan obat yang sedang dialami atau yang pernah dialami.

4. Pembagian doorprize

Pembagian doorprize kepada para peserta yang dapat menjawab pertanyaan terkait materi sosialisasi yang telah disampaikan tentang penggunaan dan penanganan obat.

5. Pembagian buku saku

Pembagian buku saku kepada setiap peserta yang hadir sebagai buku pegangan supaya peserta mudah mengingat tentang penggunaan dan penanganan obat yang benar. Buku saku 
dicetak dengan ukuran yang tidak terlalu besar dan berwarna sehingga lebih mudah untuk dibawa dan memudahkan pemahaman pembaca.

\section{HASIL DAN DISKUSI}

Program pengabdian kepada masyarakat ini dimulai dengan koordinasi antara tim pengusul dan kepala sekolah SMA Theresiana I Semarang. Pada saat koordinasi dilakukan pembahasan tentang topik permasalah dan usulan penyelesaiannya, sehingga diputuskan untuk melakukan kegiatan sosialisasi DAGUSIBU. Sosialisasi DAGUSIBU dengan cara penyuluhan tentang penggunaan dan penanganan obat yang benar serta pembagian buku saku DAGUSIBU (DApatkan, GUnakan, SImpan, BUang) bagi guru dan karyawan SMA Theresiana I Semarang telah dilaksanakan pada hari Kamis, tanggal 6 Desember 2018. Kegiatan dilaksanakan di ruang pertemuan SMA Theresiana I, jalan Mayjend Sutoyo 69 Semarang. Kegiatan dimulai dengan pembukaan dan sambutan oleh kepala sekolah SMA Theresiana I Semarang yang menjelaskan tujuan diadakannya kegiatan sosialisasi DAGUSIBU. Total peserta yang hadir yaitu 25 orang terdiri dari guru dan karyawan SMA Theresiana I Semarang. Total guru dan karyawan SMA Theresiana I Semarang yaitu 28 orang sehingga persentase kehadiran peserta adalah sebanyak $89,3 \%$. Foto peserta sosialisasi dapat dilihat pada gambar 1.

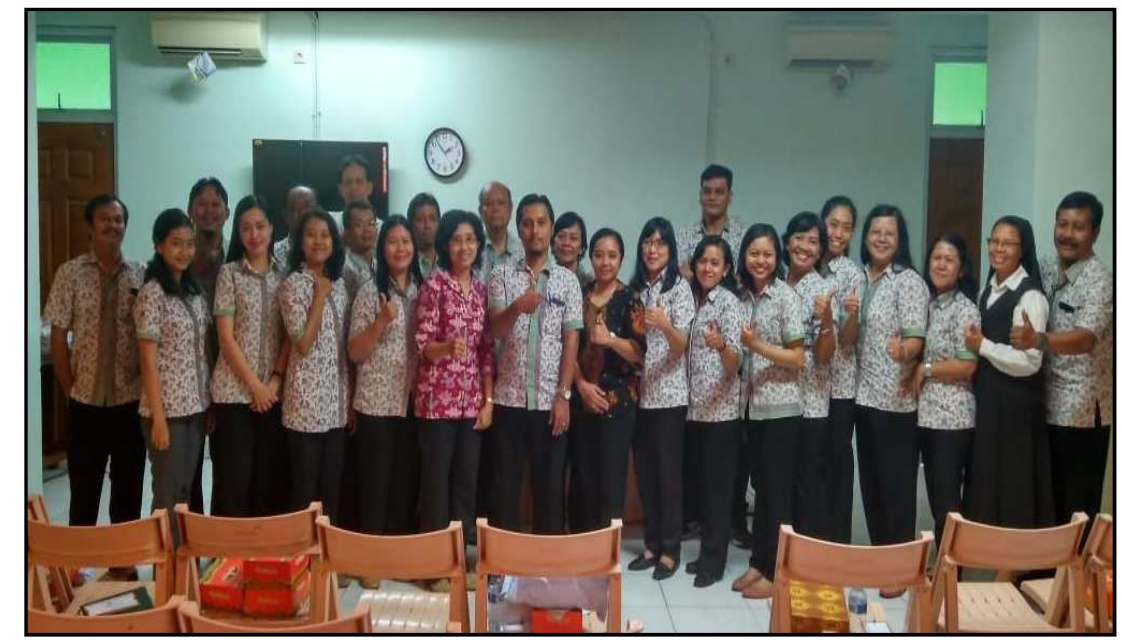

Gambar 1. Peserta sosialisasi DAGUSIBU.

Kegiatan sosialisasi diawali dengan penjelasan tentang arti dari singkatan DAGUSIBU, tempat membeli obat yang aman yaitu pada fasilitas kefarmasian (apotek, rumah sakit, puskesmas, klinik utama, toko obat) serta penggolongan obat. Penggolongan obat dibagi menjadi empat, yaitu obat bebas, obat bebas terbatas, obat keras, dan obat narkotika 
(Sumarsono, 2015). Para peserta ditekankan tentang perbedaan tiap golongan obat tersebut dan bagaimana cara mendapatkannya, wajib atau tidaknya menggunakan resep dokter (Maziyyah, 2015). Pada saat menjelaskan tentang penggolongan obat narkotika lebih ditekankan tentang fungsi obat secara umum dan efek samping berbahaya yang mungkin ditimbulkan apabila mengkonsumsi obat golongan narkotika tidak sesuai dengan aturan pakai. Hal ini yang memungkinkan obat golongan narkotika disalahgunakan yaitu mempunyai potensi menyebabkan penurunan atau perubahan kesadaran dan dapat menimbulkan ketergantungan (Syamsuni, 2016). Pada kegiatan ini juga dijelaskan tentang penggolongan obat tradisional yang terdiri dari jamu, obat herbal terstandar dan fitofarmaka (Chaerunissa, dkk., 2011). Para peserta diharapkan memahami macam-macam penggolongan obat sehingga dapat membedakan setiap jenis obat yang akan dibeli. Foto kegiatan sosialisasi DAGUSIBU dapat dilihat pada gambar 2.

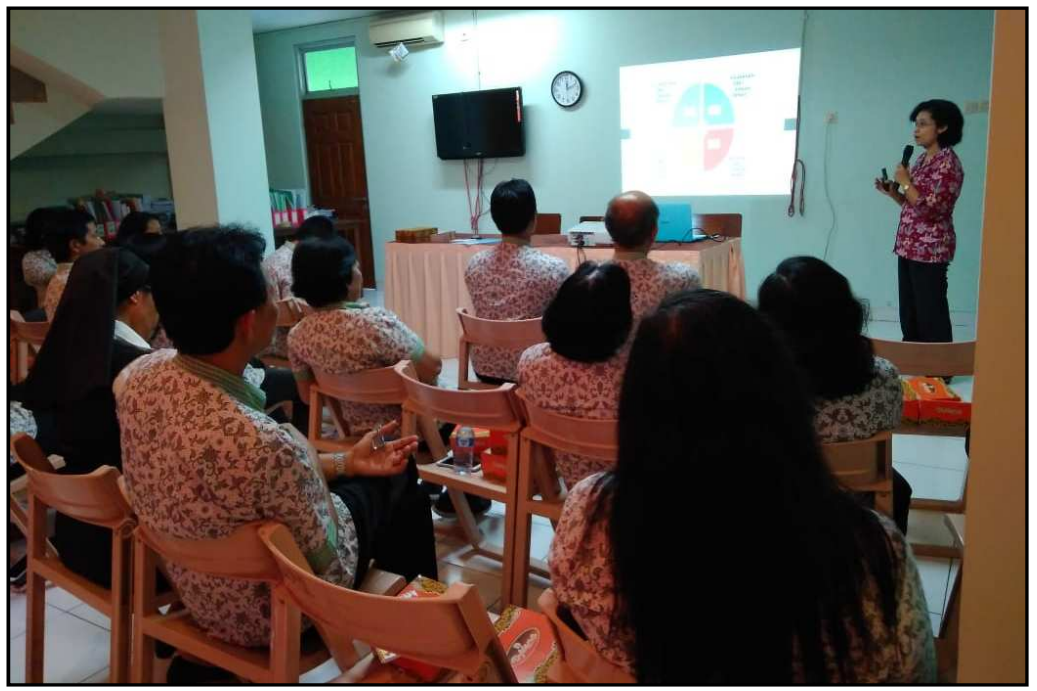

Gambar 2. Kegiatan sosialisasi DAGUSIBU.

Pada saat sosialisasi dijelaskan juga tentang hal-hal yang harus diperhatikan dalam melakukan penangan obat, yaitu melakukan pemeriksaan tanggal kadaluarsa obat dan memperhatikan cara penggunaan obat dengan benar. Tim pelaksana menjelaskan dan mempraktekkan cara pemakaian obat pada bentuk sediaan khusus. Obat dalam bentuk sediaan khusus tersebut, yaitu sediaan obat tetes mata, suppositoria, salep mata, tetes hidung, semprot hidung, semprot mulut, dan tetes telinga (Lutfiyati, et al., 2017). Cara penggunaan obat-obat tersebut penting untuk dijelaskan karena sering terjadi kesalahan cara pemakaiannya disebabkan kurangnya informasi terkait hal tersebut. Penjelasan selanjutnya adalah tentang penyimpanan obat dengan benar sesuai dengan petunjuk penyimpanan yang tertera pada kemasan obat. Penyimpanan obat yang tidak sesuai dapat menurunkan stabilitas obat yang pada akhirnya akan 
berpengaruh pada efektivitas obat tersebut dalam memberikan efek terapi. Penyimpanan obat yang tidak memerlukan kondisi khusus sebaiknya disimpan pada kotak obat yang terlindung dari paparan sinar matahari langsung dan tidak terjangkau oleh anak-anak. Materi terakhir yang diberikan yaitu menjelaskan tentang cara membuang obat dengan benar supaya tidak disalahgunakan oleh orang lain. Pada saat akan membuang obat terlebih dahulu harus menghilangkan semua label dari wadah obat, untuk obat berbentuk padat harus dihancurkan terlebih dahulu sebelum dibuang, sedangkan untuk obat berbentuk cair dibuang ke dalam saluran air (Lutfiyati et al. 2017).

Kegiatan sosialisai dilanjutkan dengan sesi diskusi dan tanya jawab. Para peserta yang hadir dalam sosialisasi DAGUSIBU sangat antusias dalam mendengarkan penjelasan dan aktif bertanya terkait penggunaan obat dan penanganannya. Hal ini diketahui dari respon peserta dalam menanggapi kegiatan ini secara positif dan antusias. Antusiasme peserta terlihat pada saat mendengarkan dan mencatat beberapa hal sesuai penjelasan yang diberikan tentang penggunaan dan penanganan obat yang benar. Banyak peserta yang aktif bertanya tentang beberapa hal antara lain terkait pengelolaan obat, penggunaan obat yang sedang dikonsumsinya, efek samping yang ditimbulkan oleh obat yang sedang dikonsumsi. Pertanyaan lain yang muncul yaitu tentang penggantiaan obat dengan zat aktif yang sama tetapi berbeda merk, perbedaan antara obat generik dan non generik, penggunaan obat herbal yang bersamaan dengan obat kimia. Beberapa guru juga bertanya tentang kriteria kemasan obat yang baik, pemilihan obat bagi pasien yang memiliki riwayat alergi obat, makanan yang aman bagi penderita sakit kolesterol serta kepatuhan dalam meminum obat, dan masih banyak lagi pertanyaan yang lain. Foto keaktifan peserta dalam sesi diskusi dan tanya jawab dapat dilihat pada gambar 3.

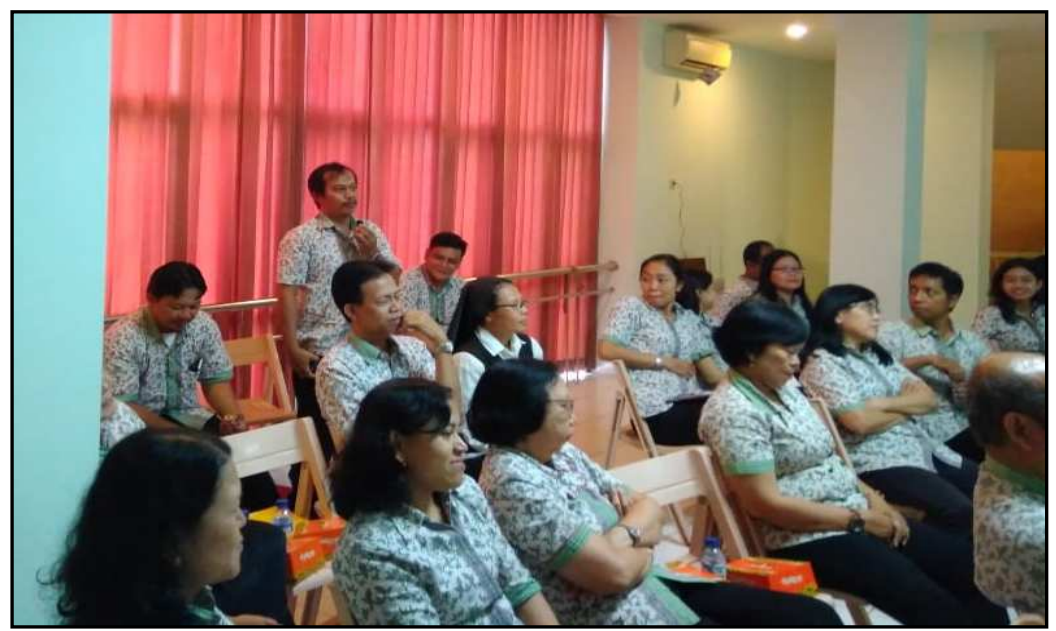

Gambar 3. Keaktifan peserta dalam sesi diskusi dan tanya jawab. 
Indonesian Journal of Community Services

E-ISSN: 2684-8619

Volume 1, No. 1, May 2019

http://jurnal.unissula.ac.id/index.php/ijocs DOI: http://dx.doi.org/10.30659/ijocs.1.1.62-72

Kegiatan sosialisasi dilanjutkan dengan acara pembagian doorprize kepada peserta penyuluhan. Doorprize diberikan kepada peserta yang dapat menjawab pertanyaan yang diajukan oleh tim pelaksana. Pertanyaan yang diajukan tentang materi yang telah disampaikan selama sosialisasi. Hal ini untuk mengetahui tingkat pemahaman peserta terkait meteri yang diberikan, selain itu doorprize yang diberikan diharapkan dapat menjadi kenang-kenangan bagi para peserta dan sebagai pengingat bahwa pernah dilakukan sosialisasi DAGUSIBU oleh Progran Studi DIII Farmasi Politeknik Katolik Mangunwijaya di SMA Theresiana I Semarang. Foto kegiatan pembagian doorprize dapat dilihat pada gambar 4.

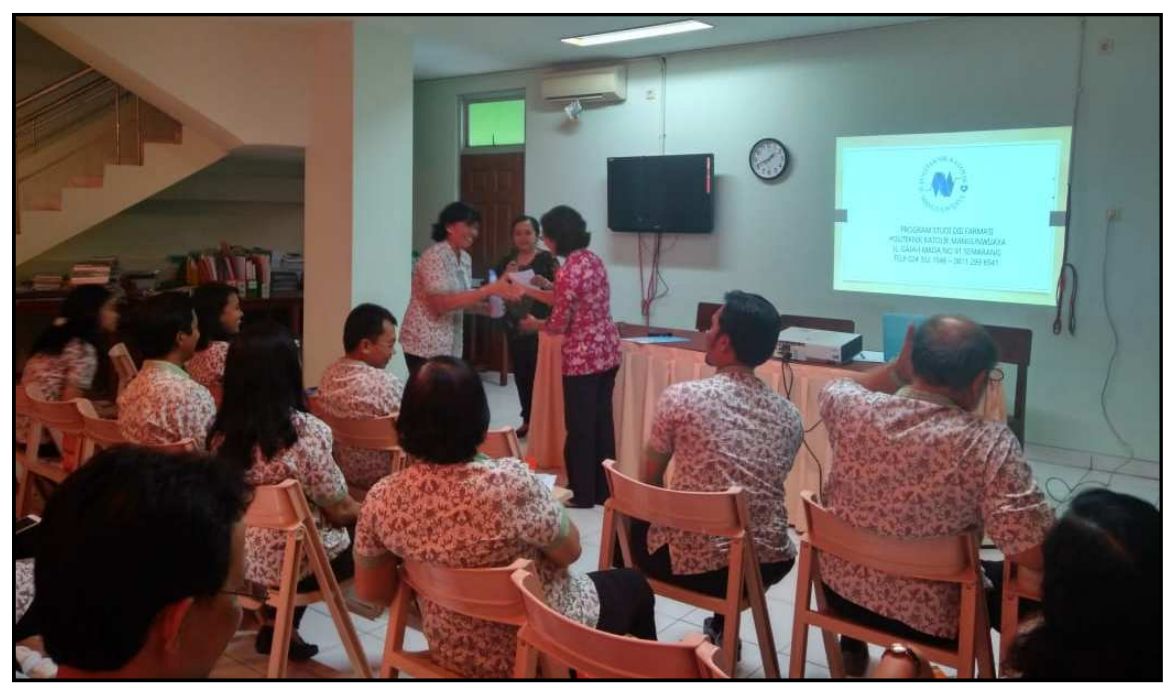

Gambar 4. Kegiatan pembagian doorprize

Kegiatan sosialisasi diakhiri dengan pembagian buku saku DAGUSIBU. Buku saku ini dapat digunakan sebagai pegangan bagi para peserta dan sebagai pengingat apabila terdapat beberapa informasi yang terlupa. Pembagian buku saku ini bertujuan agar setiap peserta dapat dengan mudah membaca hal-hal terkait penggunaan dan pengelolan obat dengan benar. Buku saku dibuat dengan ukuran kecil sehingga mudah dibawa ke mana-mana dan dibuat berwarna sehingga lebih jelas dan nyaman untuk dibaca. Foto buku saku yang dibagikan kepada peserta sosialisasi dapat dilihat pada gambar 5 . 


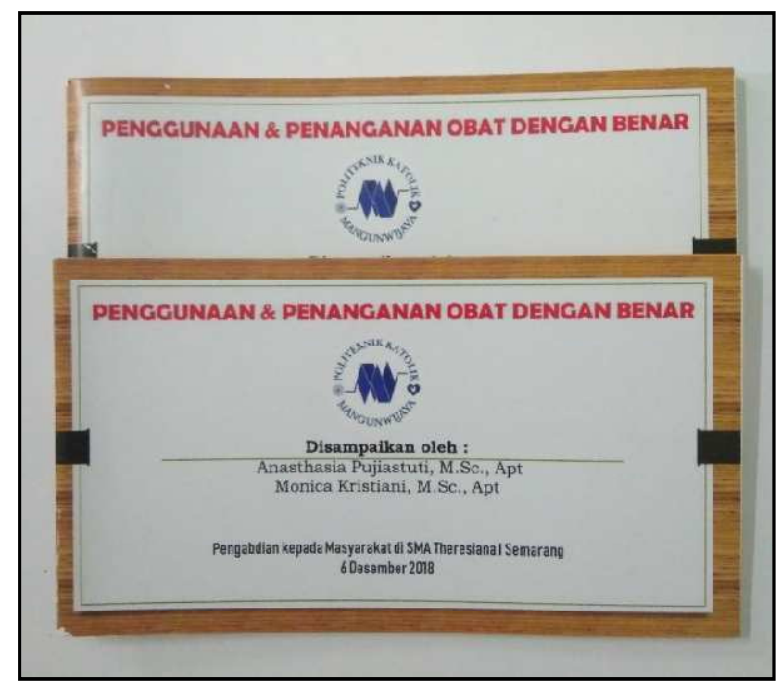

Gambar 5. Buku saku Penggunaan dan Penanganan Obat dengan Benar.

Pada saat awal dilakukan penyuluhan diketahui bahwa tidak semua peserta paham dan mengerti tentang penggunaan dan penanganan obat dengan benar. Setelah pelaksanaan penyuluhan seluruh peserta menjadi mengerti bahwa pembelian obat yang benar adalah di sarana kefarmasian karena terjamin keaslian dan keamanan obatnya. Beberapa peserta yang kurang paham tentang penggunaan obat yang benar terutama untuk bentuk sediaan obat non oral, misalnya penggunaan obat tetes mata dan tetes telinga yang benar, serta posisi badan pada saat pengaplikasian obat setelah dilakukan penyuluhan menjadi lebih mengerti. Beberapa peserta penyuluhan yang pada awalnya kurang paham tentang penyimpanan obat yang benar serta tanda-tanda obat yang telah mengalami kerusakan, serta batas aman penggunaan obat setelah dibuka dari kemasan aslinya setelah pelaksanaan kegiatan menjadi lebih paham. Penyimpanan yang tidak tepat dapat merusak obat. Mayoritas obat sebaiknya disimpan dalam suhu ruang di kotak obat yang tidak dapat dijangkau oleh anak-anak, namun ada sebagian obat yang harus disimpan dalam lemari es untuk menjaga obat tetap berkhasiat. Secara umum obat tidak boleh terpapar sinar matahari langsung, oleh karena itu, obat perlu disimpan di tempat tertutup dan kering. Obat juga harus disimpan di tempat aman, terhindar dari balita agar tidak dimakan sembarangan. Saat menerima obat hendaknya dibaca informasi terkait penggunaan obat dan cara penyimpanan yang tertera di kemasan obat. Pada saat membeli obat seharusnya menerima kemasan obat secara lengkap karena semua informasi tentang obat tersebut tercantum dalam kemasan. Sebagian besar peserta telah paham tentang cara pembuangan obat yang telah rusak atau kadaluarsa, yaitu dengan merusak obat dan bungkusnya. Hal ini telah dipahami 
peserta bahwa obat yang dibuang sembarangan dapat mencemari lingkungan. Obat dan kemasan yang akan dibuang jika tidak dirusak dapat memungkinkan untuk disalahgunakan oleh orangorang yang tidak bertanggung jawab.

\section{KESIMPULAN}

Berdasarkan hasil pelaksanaan program pengabdian kepada masyarakat dapat disimpulkan bahwa kegiatan sosialisasi DAGUSIBU dengan cara penyuluhan tentang penggunaan dan penanganan obat yang benar berjalan dengan baik dan lancar. Hal ini diketahui dari tingkat kehadiran dan keaktifan para peserta. Total peserta yaitu 25 orang, terdiri dari guru dan karyawan SMA Theresiana I Semarang. Total guru dan karyawan SMA Theresiana I Semarang yaitu 28 orang sehingga persentase kehadiran peserta adalah sebanyak 89,3\%. Para peserta yang hadir sangat antusias dalam mendengarkan penjelasan dan aktif bertanya terkait penggunaan obat dan penanganannya. Sosialisasi ini meningkatkan pemahaman peserta tentang pengelolaan obat dengan benar. Hasil dari kegiatan ini adalah diharapkan bagi peserta dapat menerapkan pengetahuan yang telah diperoleh dalam lingkungan keluarga dan masyarakat. Hal ini dapat mendukung terwujudnya program pemerintah dalam peningkatan pelayanan kesehatan bagi masyarakat.

\section{UCAPAN TERIMAKASIH}

Ucapan terima kasih dan penghargaan kami sampaikan kepada:

1. Lembaga Penelitian dan Pengabdian Masyarakat (LPPM) Politeknik Katolik Mangunwijaya yang telah memberikan dana dalam pelaksanaan Program Pengabdian Masyarakat ini.

2. Ketua Program Studi DIII Farmasi Politeknik Katolik Mangunwijaya yang telah memberikan ijin untuk melaksanakan kegiatan ini.

3. Mahasiswa Program Studi DIII Farmasi Politeknik Katolik Mangunwijaya yang ikut serta dalam persiapan dan pelaksanaan Program Pengabdian Masyarakat sehingga kegiatan berjalan dengan lancar.

4. Kepala sekolah SMA Theresiana I Semarang (Bernardus Anindyo Windi, S.Pd) beserta guru dan karyawan SMA Theresiana I Semarang yang telah ikut berpartisipasi aktif dalam kegiatan ini. 


\section{DAFTAR PUSTAKA}

Chaerunissa, A.Y., Surahman, E., Imron, S.S. (2011). Farmasetika Dasar Konsep Teoritis dan Aplikasi Pembuatan Obat. Bandung: Widya Padjadjaran.

Jimmy.(2015). Penyalahgunaan Narkoba di kalangan Remaja (Studi kasus pada Badan Narkotika Nasional Kota Tanjungpinang). Program Studi Ilmu Sosiologi Fakultas Ilmu Sosial Dan Politik Universitas Maritim Raja Ali Haji Tanjungpinang. Diakses tanggal 20 Juni 2018.http://jurnal.umrah.ac.id/wp-content/uploads/gravity_forms/1ec61c9cb232a03a96d0947c6478e525e/2015/09/E-jurnal-jimmy.pdf.

Kementerian Kesehatan Republik Indonesia.(2009).Undang-Undang Republik Indonesia Nomor 36 Tahun 2009 tentang Kesehatan.Jakarta: Kemenkes RI.

Lutfiyati, H., Yuliatuti, F., Dianita, P.S..(2017). Pemberdayaan Kader PKK dalam Penerapan DAGUSIBU (Dapatkan, Gunakan, Simpan, dan Buang) Obat dengan Baik dan Benar.The $6^{\text {th }}$ University Research Colloquium. Universitas Muhammadiyah Magelang. diakses tanggal 15 November 2018.http://journal.ummgl.ac.id/index.php/urecol/article/view/1562/672.

Maziyyah, N.. (2015) Penyuluhan Penggunaan Obat yang Benar (DAGUSIBU) di Padukuhan Bakalan, Mlati, Sleman, Yogyakarta.Laporan Kegiatan Pengabdian Masyarakat. Program Studi Farmasi, Fakultas Kedokteran dan Ilmu Kesehatan Universitas Muhammadiyah Yogyakarta.diakses tanggal 11 Januari 2019.http://repository.umy.ac.id/bitstream/handle/123456789/4169/LAPORAN\%20pen gabdian\%20DES\%202015.pdf?sequence=1.

Pemerintah Republik Indonesia. (2009). Peraturan Pemerintah Nomor 51 Tahun 2009 tentang Pekerjaan Kefarmasian.Jakarta: Pemerintah RI.

Permatasari. (2017). Efektivitas Penggunaan Media Sosial Berupa Facebook dan Instagram untuk meningkatkan Pengetahuan Mahasiswa Non Kesehatan tentang Dagusibu di Universitas Muhammadiyah Purwokerto. Diakses tanggal 20 Juni 2018.http://repository.ump.ac.id/4163/2/Rita\%20Permatasari BAB\%20I.pdf.

PP IAI. (2014). Pedoman Pelaksanaan Gerakan Keluarga Sadar Obat, Pengurus Pusat Ikatan Apoteker Indonesia. Diakses tanggal 21 Juni 2018. http://iaisumbar.net/site/wpcontent/uploads/2014/09/GKSO-Pedoman-Pelaksanaan.pdf.

Sumarsono, T.. (2015). Pengantar Studi Farmasi. Jakarta: Penerbit Buku Kedokteran EGC. Syamsuni, H.A.. (2016). Ilmu Resep. Jakarta: Penerbit Buku Kedokteran EGC. 